\title{
Turbulence Modeling in Side-Entry Stirred Tank Mixing Time Determination
}

\author{
Suci Madhania, Ni'am Nisbatul Fathonah, Kusdianto, Tantular Nurtono, and Sugeng Winardi* \\ Chemical Engineering Department, Institut Teknologi Sepuluh Nopember, Kampus ITS Sukolilo, Surabaya, 60111, Indonesia
}

\begin{abstract}
Mixing is one of the critical processes in the industry. The stirred tank is one of the operating units commonly used in the mixing process. Several factors greatly influence the efficiency of the stirred tank, including the stirred-tank design, operating conditions, and working fluid properties. The side-entry stirred tank is widely applied in industry, among others; the processing of crude oil in the refinery industry, water-molasses mixing in the bioethanol industry, pulp stock chest in the pulp and paper industry, and anaerobic digester for biogas reactors. Mixing time is one of the critical parameters used in the design of the stirred tank. This research will model mixing time in a flat bottomed-cylindrical side-entry stirred tank with dimensions $D=40 \mathrm{~cm}$ and $T$ $=40 \mathrm{~cm}$ using CFD ANSYS 18.2 by applying the Standard $k-\varepsilon$ (SKE) and Realizable $k-\varepsilon$ (RKE) turbulence models. The stirrer used is a three-blade marine propeller $d=4 \mathrm{~cm}$ which is an axial type impeller. The phenomenon of mixing in the side-entry stirred tank, qualitatively described through computational prediction results in the form of flow profiles and tracer density change contours locally. Moreover, quantitatively indicated by mixing time validated using experimental data carried out by the conductometry method. The computational prediction shows that the mixing time modeled using the SKE turbulence model shows a similarity level of $68.16 \%$, while the RKE turbulence model shows $31.94 \%$.
\end{abstract}

\section{Introduction}

Mixing is one of the crucial processes and commonly found in almost all industries. An example is a process of mixing raw materials inside fermenter in the bioethanol industry, pulp stock chest in the pulp and paper industry, and anaerobic digester for biogas reactors. The stirredtank is one of the operating units commonly used in the mixing process. Many researchers have conducted research to improve mixing efficiency in stirred tanks. Based on the studies that have been carried out, the effectiveness of the mixing process in a stirred tank is influenced by, among others, tank design includes the position of the stirrer installation (Madhania et al., 2017), the existence of baffles (Pukkella et al., 2019), the type of stirrer (Sossa-Echeverria and Taghipour, 2015; Reviol et al., 2018), the working fluid (Madhania et al., 2019b) and stirrer rotational speed (Madhania et al., 2019a).

One of the essential parameters used to determine the performance of a stirred tank is mixing time. The mixing time is defined as the time required for achieving a certain degree of homogeneity of tracer inserted in a stirred vessel. Some experimental methods in the mixing - time determination inside a stirred-tank among others, are the conductometry method (Collignon et al., 2010), colorimetry method (Kraume and Zehner, 2001), electrical resistance tomography method (Naeeni and Leila, 2019), pH measuring method (Vallejos et al., 2005) and planar laser-induced fluorescence method (Hu et al., 2012).

Research regarding the performance of stirred tanks is growing as the development of computational technology and mathematical models, and Computational Fluid Dynamic (CFD) is an advanced instrument for dealing with fluid flow problems. In the presence of a stirrer, most of the stirred tank operates in turbulent conditions; hence, the selection of the turbulence model for computational prediction is an essential element that must be considered. Some study has been done in the turbulent model evaluation to describe the turbulent flow in a stirred tank computationally (Coroneo et al., 2011; Singh et al., 2011; Lane, 2017; Cortada-Garcia et al., 2017).

This research aim of evaluating two turbulent models (the Standard $k-\varepsilon$ and Realizable $k-\varepsilon$ ) in mixing-time determination inside a flat bottomed-cylindrical stirred tank $(\mathrm{D} / \mathrm{T}=0.1$ and $\mathrm{T}=40 \mathrm{~cm})$ equipped with a threebladed propeller mounted from a side (side-entering) computationally using CFD then validated with experimental results.

\section{Material and Methods}

Determination of mixing-time inside a stirred-tank was conducted both computationally and experimentally. The reviewed stirred tank system in this study is a flat

\footnotetext{
* Corresponding author: swinardi@chem-eng.its.ac.id
} 
bottomed-cylindrical tank with a diameter of $40 \mathrm{~cm}$, and the liquid level is $40 \mathrm{~cm}$. The three-blade marine propeller with a diameter of $4 \mathrm{~cm}$ was used and installed on the side of the tank.

\subsection{Computational investigation}

Mixing time prediction of the stirred tank was performed using Ansys Fluent 18.2 in a Hewlett-Packard Z640 workstation. The geometry refers to the stirred-tank in the experimental work, as shown in Figure 1, and it was generated using Ansys Design Modeler. Furthermore, the computational domain was divided into volume control using Ansys Meshing. The numerical predictions were performed using mesh size that has passed the grid independence test.

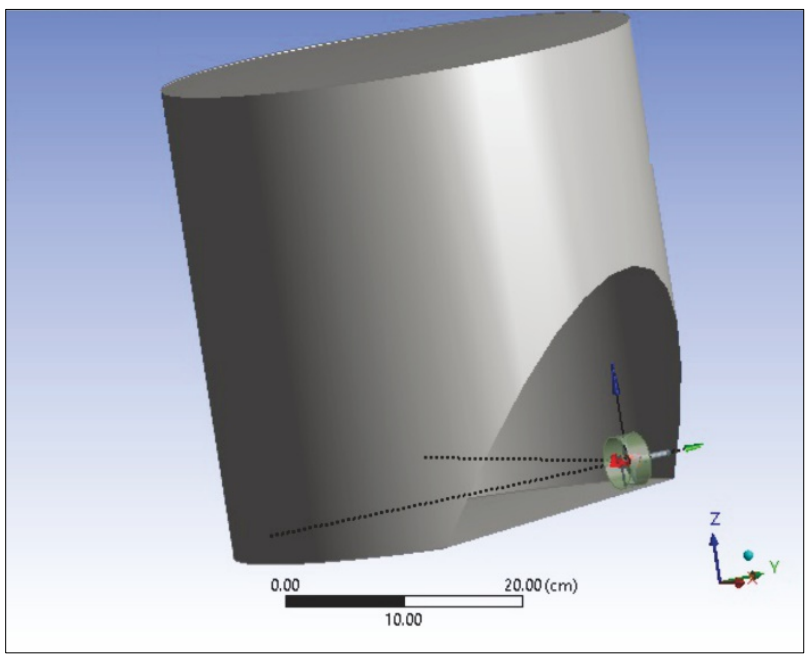

Figure 1. Computational domain

Water and $\mathrm{HCl}$ were used as the working fluids with properties shown in Tabel 1. A multiphase mixture model was applied to model the flow of two liquids with different density and viscosity, where water was set as the primary phase while $\mathrm{HCl}$ as the secondary phase.

Table 1. The working fluid properties

\begin{tabular}{ccc}
\hline Margin & Water & HCl 37\% \\
\hline Density $\left[\mathrm{kg} / \mathrm{m}^{3}\right]$ & 998.2 & 1180 \\
Viscosity $[\mathrm{kg} / \mathrm{m} . \mathrm{s}]$ & 0.001003 & 0.00168 \\
\hline
\end{tabular}

Moving Reference Frame (MRF) method was used to treat a moving zone and stationary zone interaction with relative lower computational cost reason. Based on finding in the turbulence model evaluation study in mechanical agitation of non-Newtonian fluid (Wu, 2011) that the standard $\mathrm{k}-\varepsilon$ (SKE) and the realizable $\mathrm{k}-\varepsilon$ (RKE) are more appropriate than other investigated turbulence models. For that reason, the SKE and RKE turbulence model was set as a computational investigation variable. The SKE model equation was proposed by Launder and Spalding (1972) while RKE by Shih et al. (1995). The calculation was done in transient mode and time step was set to $0.1 \mathrm{~s}$

\subsection{Experimental work}

The schematic view of the experiment shown in Figure 2. The working fluid inside the tank is water, and $\mathrm{HCl} 37 \%$ solution was used as a tracer to determine the mixing-time. A probe was placed at the observation point to detect the local fluid conductivity every 1 -second interval and connected to a computer through the data acquisition (DAQ) device. Stirring rotational speed was set at 400 rpm, and its accuracy was ensured with a tachometer.

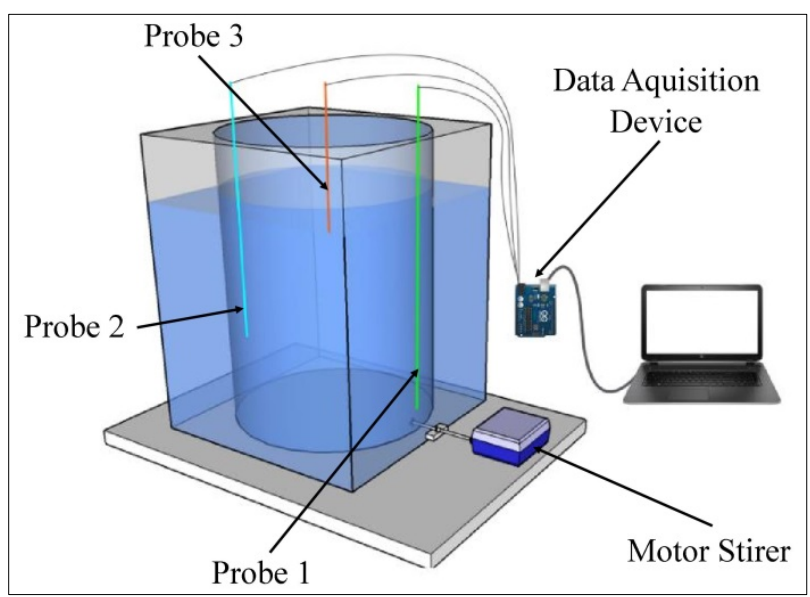

Figure 2. The experimental setup schematic view

\section{Results and Discussion}

The mixing-time prediction of stirred tanks computationally was analyzed through observation points and observation planes, as shown in Figure 3. The observation point location was determined based on the probe position on the experimental work. The observation plane consists of a vertical plane and a radial plane.

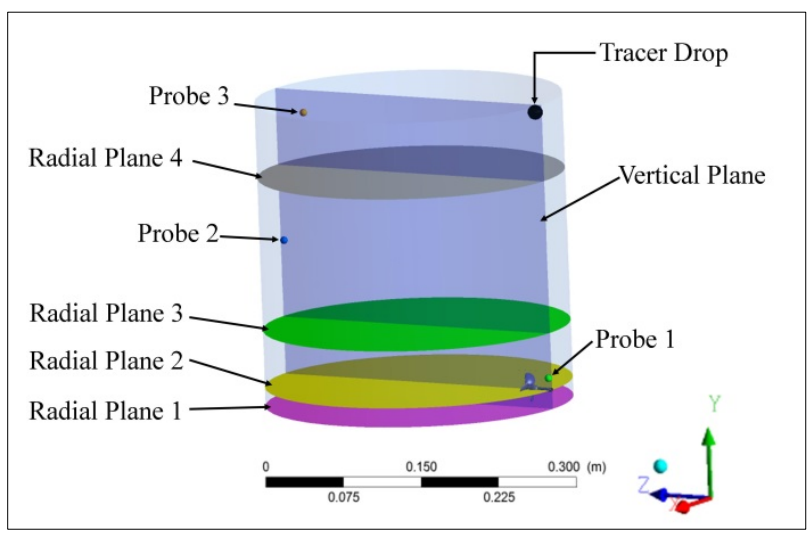

Figure 3. The observation point (probe) and observation plane (vertical and radial)

\subsection{Mixing time}

The computational prediction of mixing time was analyzed based on the local $\mathrm{HCl}$ volume fraction change at the three observation points, as shown in Figure 4. Based on Figure 4, it can be seen that in the first 60 seconds of stirring there was a change in the local $\mathrm{HCl}$ fraction volume with the highest range; then a decrease occurred until it tends to stable at stirring time of about 
100 seconds. It means that $\mathrm{HCl}$ detected at the three observation points at the beginning of stirring has a high concentration, and along with increasing time the mixing, $\mathrm{HCl}$ detected decreases and tends to be uniform. The phenomenon of a reduced fraction of $\mathrm{HCl}$ volume discovered at the observation point is because $\mathrm{HCl}$ has been distributed in almost all tanks.

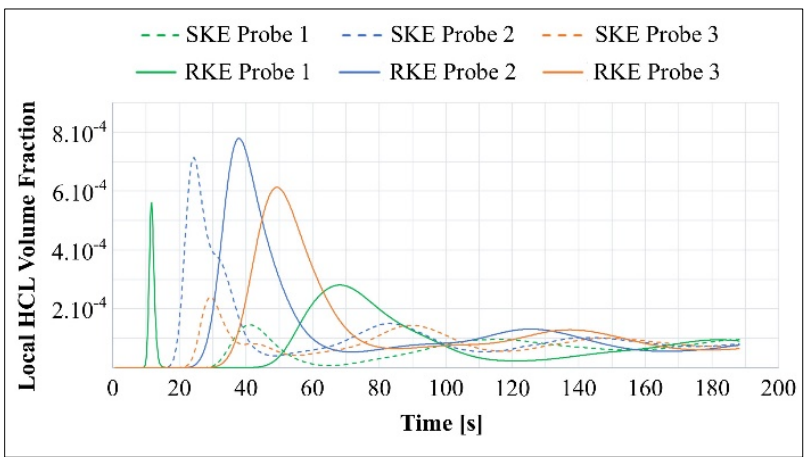

Figure 4. The prediction of mixing time computationally

Figure 4 shows the comparison results of the numeric solution which applied the SKE and RKE turbulence models, both of the graphs generally shows the same trend with a slight difference in time of $\mathrm{HCl}$ detection, where SKE shows reach a stable chart earlier than RKE. The initial condition of the steady graph can be confirmed as the achievement of mixing time. The mixing time prediction on SKE solution was $129.2 \mathrm{~s}$ while $164.7 \mathrm{~s}$ for RKE.

On experimental work, mixing time was analyzed based on changes in the local conductivity value of the three observation points, as shown in Figure 5.

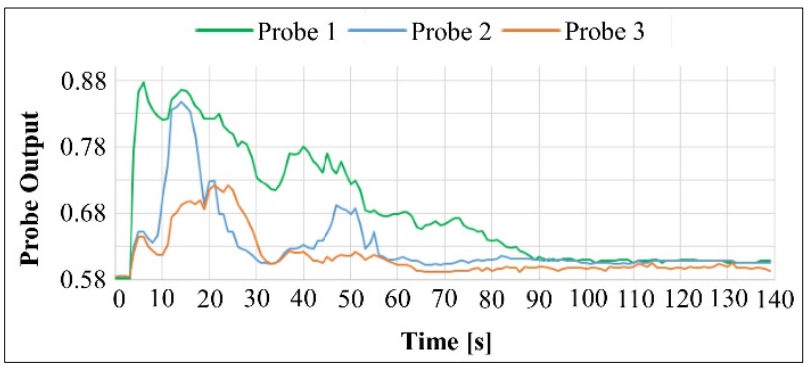

Figure 5. The mixture's conductivity changes at any time until the mixing time is reached

Based on Figure 5, it can be seen that at the beginning of the stirring, there is an increase in the conductivity value of all observation points, which indicated that $\mathrm{HCl}$ was detected in high concentrations. The longer the stirring time, the smaller the conductivity value and the graph tend to show a stable condition. This phenomenon indicates that the longer the stirring time, the detected $\mathrm{HCl}$ concentration gets smaller and tends to be uniform throughout the observation points and based on the experiment, the mixing time is reached in $98 \mathrm{~s}$. Based on the graphical comparison of the increase in the conductivity value of each observation point, it can be seen that the probe one shows the highest graph then probe two and probe three in sequence. It indicates that the $\mathrm{HCl}$ was carried along with the flow towards the bottom of the tank through the propeller (adjacent to the probe 1) when reaching the bottom wall, the current changed its direction to the positive axial direction towards the tank wall where observation points two and three are located. The phenomenon corresponds to the flow pattern shown in Figure 6. The movements of fluid flow induce the $\mathrm{HCl}$ evenly distributed throughout the tank.

In general, the tendency in the graph shows similarity both the experimental work and computational investigation even though there are slight differences in the behavior of $\mathrm{HCl}$ detection at the observation point at the beginning of stirring. Based on the mixing time, computational predictions using SKE turbulence models show closer results with experimental data than RKE models. The degree of similarity of computational predictions with experimental results is expressed as a percentage of similarity level. It indicates the ratio of the deviation between simulation and experimental result to experimental data. The higher the similarity level, the closer to the experimental results. The SKE turbulence model shows a similarity level of $68.16 \%$, while the RKE turbulence model shows 31.94\%

\subsection{Flow pattern}

The phenomenon of the time difference of $\mathrm{HCl}$ detected at each observation point can be associated with the $\mathrm{HCl}$ distribution inside the tank. The $\mathrm{HCl}$ distribution was analyzed through a computational investigation based on the velocity vector that was forming the flow pattern in the vertical observation plane, as shown in Figure 6.

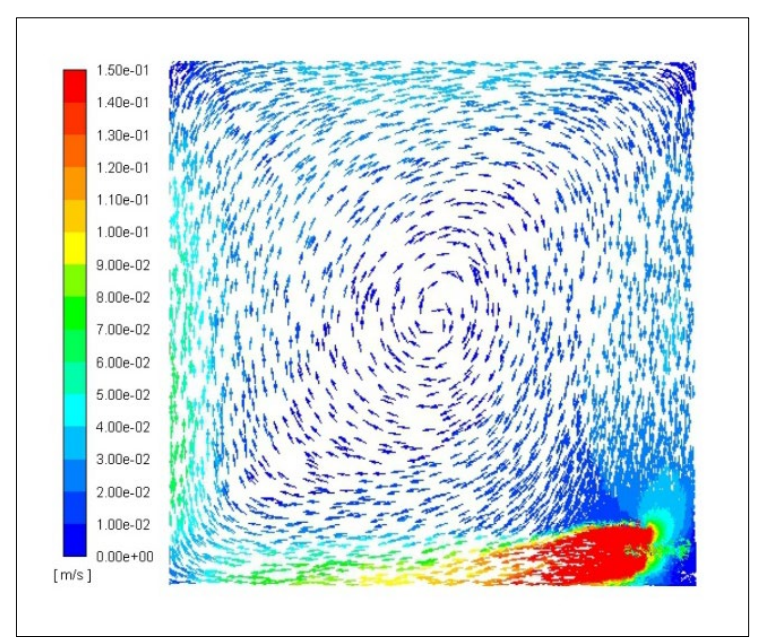

Figure 6. Velocity vector analysis of vertical plane

Based on the flow pattern that forms in the vertical observation plane, it can be seen that flows of fluid moves from the propeller to the positive axial direction towards the wall, When the flow hit the wall, the flow changed its direction towards the fluid surface and returned towards the bottom of the tank entering the propeller backside, so on until the flow forms one loop circulation. Based on the phenomenon of movement of fluid flow in the stirred tanks, indicating the $\mathrm{HCl}$ carried over the flow of fluid following the flow pattern, Therefore, in the first 20 seconds of stirring, $\mathrm{HCl}$ was detected by the probe one, then in the probe two and probe three in sequence, as shown in Figure 4 and Figure 5. 
The flow pattern that formed in the four radial observation plane located at different heights from the bottom of the tank is shown in Figure 7 . In the radial observation plane located at the tank base $(\mathrm{H}=0)$, the bulk of the flow with higher velocity moves from the propeller in the positive axial direction toward the wall, then a small part of it turned towards the propeller with the movement anticlockwise while most other streams move upwards towards the surface. The same flow pattern is likewise shown by the radial observation plane located at $\mathrm{H}=$ $0.025 \mathrm{~m}$ where that plane intersects the propeller axis, with a slight difference shown in the number of vectors and the stream velocity. While the flow pattern is shown on the radial observation plane located on the upper of the propeller $(\mathrm{H}=0.1 \mathrm{~m})$, it is seen that there is a flow motion with counter-clockwise then forming one loop circulation. Different flow patterns are shown in the radial observation plane located at an elevation of $0.35 \mathrm{~m}$ from the tank base, where the direction of flow looks uniform, as shown in Figure 7. It signifies that at that height, the direction of the flow reverses according to the circulation depicted in Figure 6.

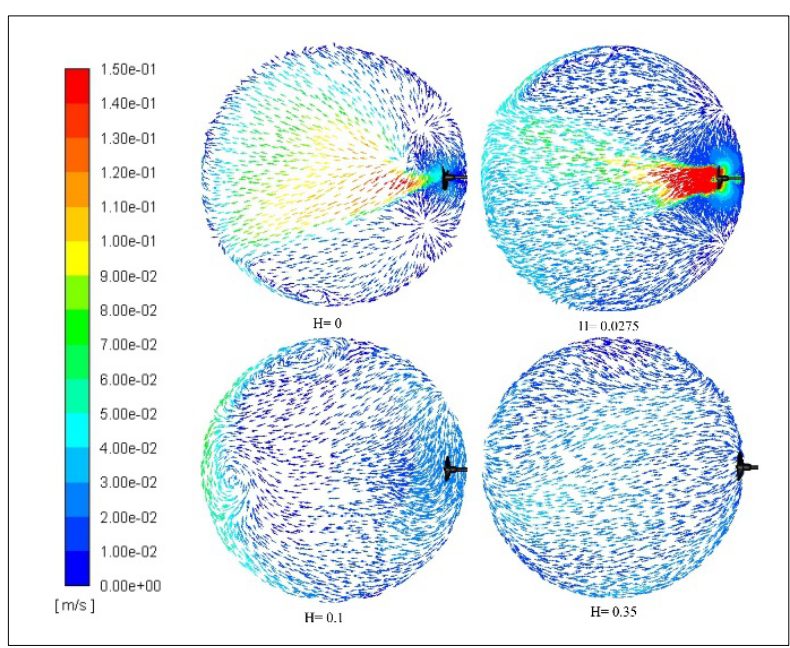

Figure 7 Velocity vector analysis of radial plane

\subsection{Mixing behavior}

The mixing behavior is showing through the density contour changes against time, as presented in Figure 8. Based on Figure 8, it can be seen that $\mathrm{HCl}$ moves downward towards the bottom of the tank, then hits the base wall of the tank, then spreads and moves to follow the flow circulation formed and disperses throughout the tank until a homogeneous condition is reached. This mixing behavior related to the trend of $\mathrm{HCl}$ detection at the observation point, as shown in Figure 4 and can explain the phenomenon of $\mathrm{HCl}$ movement inside the tank.

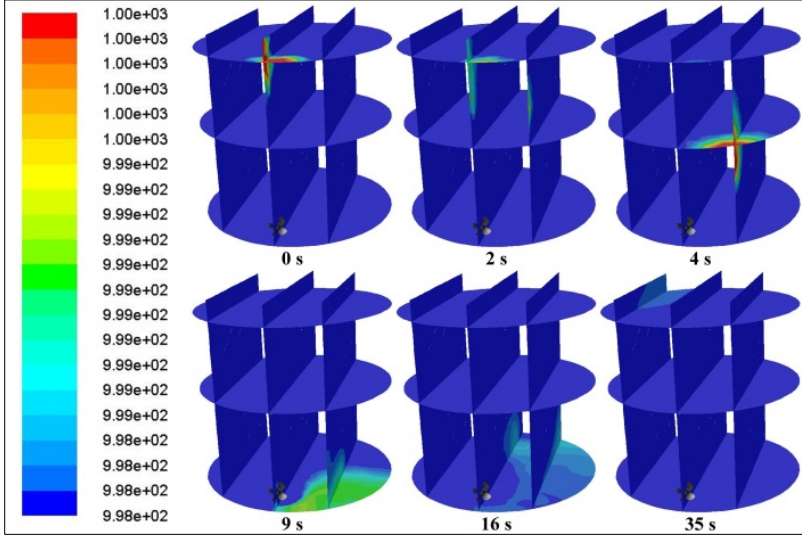

Figure 8. Density contour

\section{Conclusion}

The prediction of mixing time inside a flat bottomed cylindrical stirred-tank equipped with a side-entry propeller has been successfully obtained both through the computational prediction and experimental work. Based on mixing-time achievement similarity level, the SKE turbulence model $(68.16 \%)$ demonstrates closer results to the experimental data than RKE (31.94\%). The flow patterns and mixing behavior inside the tanks have been illustrated through computational prediction.

\section{References}

Collignon, M. L., D. Dossin, A. Delafosse, M. Crine and D. Toye; "Quality of Mixing in a Stirred Bioreactor for Animal Cells Culture: Heterogeneities in a Lab Scale Bioreactor and Evolution of Mixing Time with Scale Up Biotechnol," Agron. Environ., 14, 585-591 (2010)

Coroneo, M., G. Montante, A. Paglianti and F. Magelli; "CFD Prediction of Fluid Flow and Mixing in Stirred Tanks: Numerical Issues about the RANS Simulations," Comput. Chem. Eng., 35, 1959-968 (2011)

Cortada-Garcia, M., V. Dore, L. Mazzei and P. Angeli; "Experimental and CFD Studies of Power Consumption in the Agitation of Highly Viscous Shear Thinning Fluids," Chem. Eng. Res. Des., 119, 171-182 (2017)

Hu, Y., W. Wang, T. Shao, J. Yang and Y. Cheng; "Visualization of Reactive and Non-reactive Mixing Processes in a Stirred Tank Using Planar Induced Fluorescence (pLIF) Technique, " Chem. Eng. Res. Des., 90, 524-533 (2012)

Kraume, M. and P. Zehner; "Experience with Experimental Standards for Measurements of Various Parameters in Stirred Tanks: a Comparative Test," Chem. Eng. Res. Des., 79, 811-818 (2001)

Lane, G. L.; "Improving the Accuracy of CFD Predictions of Turbulence in a Tank Stirred by a Hydrofoil Impeller, " Chem. Eng. Sci., 169, 188-211 (2017)

Launder, B. E. and D. B. Spalding; Lectures in Mathematical Models of Turbulence, Academic Press, London, UK (1972)

Madhania, S., T. Nurtono, A. B. Cahyani, Carolina, Y. Muharam, S. Winardi and W. W. Purwanto; "Mixing 
Behaviour of Miscible Liquid-liquid Multiphase Flow in Stirred Tank with Different Marine Propeller Installment by Computational Fluid Dynamics Method," Chemical Engineering Transactions, 56, 1057-1062 (2017)

Madhania, S., T. Nurtono, Y. Muharam, S. Winardi and W. W. Purwanto; "Computational Study of the Timedependent Flow Field of a Water-Molasses Mixture Inside a Stirred Vessel," International Journal of Technology, 10, 561-570 (2019a)

Madhania, S., Y. Muharam, S. Winardi and W. W. Purwanto; "Mechanism of Molasses-Water Mixing Behavior in Bioethanol Fermenter. Experiments and CFD Modeling," Energy Reports, 5, 454-461(2019b)

Naeeni, S. K. and P. Leila; "Experimental and Numerical Investigation on Mixing of Dilute Oil in Water Dispersions in a Stirred Tank," Chem. Eng. Res. Des., 147, 493-509 (2019)

Pukkella, A. K., R. Vysyaraju, V. Tammishetti, B. Rai and S. Subramanian; "Improved Mixing of Solid Suspensions in Stirred Tanks with Interface Baffles: CFD Simulation and Experimental Validation," Chem. Eng. J., 358, 621633 (2019)

Reviol, T., S. Kluck and M. Böhle; "A New Design Method for Propeller Mixers Agitating Non-Newtonian Fluid Flow, " Chem. Eng. Sci., 190, 320-332 (2018)

Shih, T.-H., W. W. Liou, A. Shabbir, Z. Yang and J. Zhu; "A New k- $\varepsilon$ Eddy Viscosity Model for High Reynolds Number Turbulent Flows," Comput. Fluids, 24, 227-238 (1995)

Singh, H., D. F. Fletcher and J. J. Nijdam; "An Assessment of Different Turbulence Models for Predicting Flow in a Baffled Tank Stirred with a Rushton Turbine" Chem. Eng. Sci., 66, 5976-5988 (2011)

Sossa-Echeverria, J. and F. Taghipour; "Computational Simulation of Mixing Flow of Shear Thinning NonNewtonian Fluids with Various Impellers in a Stirred Tank," Chem. Eng. Process. Process. Intensif., 93, 66-78 (2015)

Vallejos, J. R., Y. Kostov, M. R. Marten and G. Rao; "Confocal Optical System: a Novel Non-Invasive Sensor to Study Mixing," Biotechnol. Prog., 21, 1531-1536 (2005)

Wu, B.; "CFD Simulation of Gas and Non-Newtonian Fluid Two-phase Flow in Anaerobic Digesters," Water Res., 44, 3861-3874 (2010)

Wu, B.; "CFD Investigation of Turbulence Models for Mechanical Agitation of Non-Newtonian Fluids in Anaerobic Digesters," Water Res., 45, 2082-2094 (2011) 